\section{Ética e metodologia na pesquisa médica}

Ethics and methodology in medical research
Sonia Vieira

CPO São Leopoldo Mandic. Rua da Abolição 1827. Bairro Swift. CEP: 13.041-610. Campinas, São Paulo, Brasil. E-mail: soniavieira@merconet.com.br

\begin{abstract}
Ethical principles should be respected in medical research as well as the development history of views concerning bioethics in Brazil and in the world. The value of the 196/96 Regulation of the National Health Council and the concern of the National Commission on Ethics in Research (Comissão Nacional de Ética em Pesquisa (CONEP) as conduct regulators of research using humans. Based on the principles and accumulated world expe rience up to now issues related to maximum partici pant protection especially concerning the health area a re approached.
\end{abstract}

Key words Medical ethics, Ethics, research
Resumo Os princípios éticos que devem ser respeitados na pesquisa médica, bem como o histórico do desenvolvimento de um pensamento sobre a bioética no Brasil e no mundo são apr esentados. São enfatizadas a importância da Resolução 196/96 do Conselho Nacional de Saúde e a preocupação da Comissão Nacional de Ética em Pesquisa (CON EP) como orienta dores para a conduta na pesquisa com seres humanos. Fundamentados naqueles princípios e na experiência mundial acumulada até agora são abordadas questões no sentido da máxima proteção ao participante de uma pesquisa em especial na área de saúde.

Palavras-chave Ética médica, Ética em pesquisa. 


\section{Introdução}

A razão do sofrimento humano talvez permaneça mistério para sempre, mas algumas formas de mitigá-lo já estão disponíveis. A ciência médica evoluiu muito nestes últimos 100 anos, graças ao entendimento de que a pesquisa é necessária. Mas o avanço de conhecimentos depende de experimentação. No entanto, quando se fala em experimentar novos métodos terapêuticos em seres humanos, ainda podem ser ouvidas algumas reações emocionais. Há quem se recuse a acreditar que se façam experimentos com pessoas: "Meu médico sabe o que faz. Jamais aplicaria em mim um tratamento que não conhece". Outros se revoltam: "Isto aqui é campo de concentração?". A reação emocional se explica: as pessoas temem o abuso. Os abusos já ocorreram, estão ocorrendo e ainda ocorrerão. Devem ser punidos, mas a pesquisa médica precisa ser feita - e sem abuso ou coerção.

Algumas pessoas exprimem a crença ingênua de que as pesquisas médicas são feitas apenas com ratos e cobaias. Até médicos com treinamento científico às vezes externam a opinião simplista de que informações advindas de experimentos in vitro e de experimentos pré-clínicos feitos com animais são definitivas, e que seria possível aplicá-las de imediato, como se fossem verdades consagradas. Não é bem assim: os resultados pré-clínicos são indispensáveis para que se inicie a pesquisa em seres humanos. No entanto, o resultado de um tratamento novo no homem só pode ser conhecido quando esse tratamento é aplicado no próprio homem.

No caso específico de drogas terapêuticas, ${ }^{1,2}$ é preciso passar pelas fases I, II, III e IV. Mesmo quando já está na fase IV de experimentação, isto é, quando a droga já é vendida no comércio, podem ocorrer efeitos colaterais sérios, não percebidos em ensaios de curto prazo. É o que aconteceu com o Vioxx, nome comercial de um antiinflamatório fabricado pela Merck Sharp \& Dohme, cujo princípio ativo é o rofecoxib, indicado no tratamento de artrite e osteoartrite, mas que, como todo antiinflamatório, foi muitas vezes usado no Brasil como panacéia. ${ }^{3} \mathrm{~A}$ droga foi aprovada pelo FDA (Food and Drug Administration) para passar à fase IV em maio de 1999, mas em fevereiro de 2001 foi feita uma reunião para discutir prováveis efeitos cardiovasculares indesejáveis, uma vez que haviam sido levantadas algumas suspeitas. No entanto, o Vioxx só foi retirado do comércio pelo próprio laboratório em outubro de 2004.

Existem mecanismos para coibir erros e abusos na experimentação com seres humanos. E para evidenciar alguns aspectos importantes da pesquisa médica, serão relatados aqui três experimentos feitos com seres humanos: primeiramente, a descoberta dos anestésicos, depois, os experimentos sobre congelamento e, por fim, o estudo de sífilis em Tuskegee. Esses relatos pretendem ilustrar três pontos que merecem consideração: 1) a pesquisa médica é absolutamente necessária; 2) tem mais de meio século a consciência de que o participante da pesquisa deve entender o que está acontecendo com ele; 3 ) hoje os médicos e muitas pessoas já têm consciência de que a pesquisa médica precisa seguir certas regras e certas leis.

\section{Os experimentos}

\section{A descoberta dos anestésicos}

Os anestésicos foram introduzidos na prática clínica de maneira curiosa. ${ }^{4}$ Conta-se que em meados do século XVIII o cidadão Gardner Quincy Colton, que se arrogava o título de professor de química, andava pela Nova Inglaterra promovendo grandes espetáculos públicos. Nesses espetáculos, oferecia às pessoas o óxido nitroso, mais conhecido como gás hilariante, porque produz embriaguês eufórica. $\mathrm{Na}$ platéia havia sempre alguns homens fortes disponíveis, para segurar aqueles que se excediam sob o efeito do gás.

Num desses espetáculos, um indivíduo de nome Samuel Cooley tornou-se agressivo após inalar o gás - e se machucou. Mas não percebeu que havia ferido, a perna, apesar do sangramento. O dentista Horace Wells, presente ao espetáculo, interessou-se vivamente pelo caso. Interrogou Cooley prolongadamente e resolveu fazer um experimento consigo mesmo. Wells precisava que lhe extraíssem um dente. Pediu então ao seu colega John Monkey Riggs que fizesse a extração, mas sob o efeito do gás hilariante. Achou a experiência tão boa que passou a usar o gás hilariante em sua clínica.

Dado o enorme sucesso, Wells resolveu mostrar o efeito anestésico do gás hilariante em uma cirurgia médica, no Hospital Geral de Massachussets. Não deu certo. O paciente acordou no meio da cirurgia, gritando de dor. Wells foi muito ridicularizado, passou a se embriagar e morreu em um hospital psiquiátrico de Nova York.

Algum tempo depois, William T. G. Morton, um dentista que estudava Medicina em Harvard e trabalhava em sua clínica odontológica para pagar os estudos, aprendeu nas aulas de Química que o éter sulfúrico tem efeito anestésico. Conhecedor da história de Wells experimentou o éter em si mesmo, 
nas pessoas da família, no cão da casa. Usou depois o éter sulfúrico em sua clínica, e confirmou o efeito anestésico. Morton pediu então ao professor de cirurgia, John Collins Warren, para anestesiar um paciente. A notícia de que um aluno de Medicina iria anestesiar um paciente encheu o auditório. Mas, desta vez, a experiência teve sucesso. Diz a história que Warren, um homem frio, emocionou-se. Entendeu que se iniciava uma nova era na história da cirurgia. Esses fatos estão sendo lembrados aqui para firmar um ponto: a pesquisa em Medicina é essencial, pois promove o avanço do conhecimento e traz enorme benefício para toda a humanidade. No entanto, não se pode esquecer um aspecto crucial da pesquisa médica: ela deve ser conduzida de maneira ética e sua aplicação em seres humanos deve ser feita eticamente.

\section{Os experimentos sobre congelamento}

Os experimentos sobre congelamento foram feitos nos campos de concentração de Dachau, entre 1942 e 1943. Pretendia-se buscar a técnica mais eficiente de aquecimento, em benefício do exército alemão que estava enfrentando o inverno europeu. Para isso, cerca de 280 a 300 prisioneiros de guerra de diversas procedências foram expostos nus a temperaturas abaixo de zero por várias horas. As vítimas gritavam de dor quando parte de seus corpos congelava. A maioria morreu, em conseqüência dos experimentos. Os resultados obtidos, por serem únicos, foram citados várias vezes na literatura especializada. No entanto, um médico americano 5 reviu os dados e publicou em 1990 um artigo em uma das mais prestigiadas revistas médicas, "The New England Journal of Medicine", mostrando que os erros metodológicos não justificavam o uso das informações obtidas. As reações à publicação mostraram que os experimentos feitos nos campos de concentração, por trazerem à tona o pior da Medicina, inspiram horror e repúdio.

Todavia, os médicos que fizeram esses experimentos foram levados ao banco de réus no Tribunal Militar Internacional de Nuremberg, constituído por oito membros, quatro titulares e quatro suplentes representantes das quatro potências vitoriosas na guerra européia, isto é, Estados Unidos da América, Inglaterra, França e União Soviética. Sabe-se que as Forças Aliadas recorreram a meios de guerra desumanos e talvez alguém ainda se pergunte se havia o direito de julgar. Não obstante, a decisão de estabelecer um processo judiciário foi um benefício, tanto para os contemporâneos como para a posterioridade. 6

O julgamento dos médicos nazistas levou à elabo- ração do Código de Nuremberg. É verdade que esse Código surgiu no calor das apoteoses e parece ter sido feito com a função de estabelecer uma base jurídica para a condenação dos médicos. Também é verdade que as idéias contidas no Código de Nuremberg não tiveram sua aplicação generalizada de imediato. O processo civilizatório não havia atingido, ainda, a ponto de exigir sua aplicação. Mas há um mérito inegável e esse está sendo trazido aqui para firmar outro ponto: em meados do século passado, já havia a consciência de que a pessoa deve entender o que o médico fará com ela e pode optar entre dar ou não seu consentimento para participar de uma pesquisa. Então já se começava a entender que um princípio fundamental da Ética, o da autodeterminação, precisava ser incorporado à pratica da Medicina.

\section{O estudo sobre sifilis em Tuskegee}

O estudo sobre sífilis foi feito na cidade de Tuskegee, Estado de Alabama, entre 1932 e 1972, para levantar dados sobre a história natural da doença. Para isso, 399 pacientes que procuraram o Serviço Público de Saúde dos Estados Unidos foram mantidos sem tratamento. Aproximadamente 200 homens sem a doença serviram como controles. Esses estudos começaram em 1932, quando a sífilis foi tratada com injeções de drogas que continham metais pesados, como arsênico e bismuto. ${ }^{7}$ A idéia prevalente era a de que o tratamento reduzia a morbidade e a mortalidade. No entanto, também se suspeitava que algumas complicações, atribuídas à doença, eram na realidade efeitos colaterais das drogas utilizadas no tratamento. Daí, a razão do estudo. Na década de 40, quando a penicilina, conhecida por ser efetiva e segura no tratamento contra a sífilis, já estava disponível, os pacientes negros e pobres - não foram tratados nem avisados, apesar de já se saber que a sífilis diminui a expectativa de vida. Esse estudo durou 40 anos e não pode ter passado desapercebido da comunidade médica. Quando denunciado por um jornalista do Washington Star, foi aberto inquérito. Formou-se uma comissão de investigação, da qual participou o Professor Katz, autor do primeiro tratado 8 importante sobre experimentação com seres humanos e que deu importante entrevista ${ }^{9}$ à revista brasileira "Ciência Hoje", em 1989. O estudo sobre sífilis de Tuskegee foi suspenso, os participantes do estudo foram então tratados e indenizados. Mas esse estudo marca outro ponto na história da experimentação com seres humanos sobre o qual queremos chamar a atenção: "a exigência da sociedade para leis que regula- 
mentem a pesquisa médica" com controle social sobre o sistema de proposição e avaliação para esse tipo de pesquisa.

As primeiras leis americanas foram promulgadas 7 em 1982. A sociedade já havia criado elementos de consciência suficientes para procurar sistematizar a pesquisa médica. Aliás, em um gesto simbólico, 25 anos depois de encerrado o estudo de Tuskegee, o Presidente dos Estados Unidos da América pediu formalmente desculpas aos afro-descendentes pelo fato de o governo americano ter financiado esse estudo sobre sífilis.

\section{A situação no Brasil}

No Brasil, as primeiras normas para a pesquisa com seres humanos foram estabelecidas pela Resolução $\mathrm{n}^{\circ} 1$ de 18 de junho de 1988 do Conselho Nacional de Saúde (CNS), órgão do Ministério da Saúde. Já havia a consciência de que era preciso pautar a experimentação com seres humanos em certas normas. Aliás, em 1986 foi publicado, por esta autora e Hossne, 10 um livro no qual se pedia essa normatização e que talvez tenha agido como catalisador para as reações que estavam prestes a ocorrer. Em 1995 foi proposta uma revisão da Resolução $1 / 88$, o que foi acatado pelo Conselho Nacional de Saúde (CNS). Foi então constituído um Grupo Executivo de Trabalho (GET) e consultadas aproximadamente 30.000 pessoas. A versão preliminar da nova resolução foi aprovada no I Congresso Brasileiro de Bioética, realizado em São Paulo em julho de 1996.10

A Resolução 196/9611 criou a Comissão Nacional de Ética em Pesquisa (CONEP) que tem, entre outras atribuições, a de zelar pelo cumprimento da Resolução, monitorar e aconselhar, sem ser policialesca. Mas talvez os pesquisadores devessem levantar ainda mais esta questão: quem efetivamente participa da pesquisa médica no Brasil? Médicos e pacientes precisam ser ressocializados?

\section{Com quem são feitos os experimentos médicos?}

A pergunta que aqui se põe é de suma importância: com quem são feitos os experimentos? Quem se presta a experimentar novas drogas ou se submeter às técnicas cirúrgicas experimentais? Essa é uma preocupação da CONEP e a Resolução 196/96 cria condições para a coleta de dados. Aliás, nos Comitês de Ética em Pesquisa (CEP) de todo o Brasil já está sendo implantado um Sistema Informatizado Nacional de Informação sobre Ética em Pesquisa
(SISNEP) envolvendo seres humanos que terá um Banco de Dados, permitindo assim, obter-se o perfil do participante de pesquisa. Mas ainda não existem estatísticas e as pesquisas publicadas nem sempre fazem estudo sociológico dos participantes. É pois, difícil, saber as motivações de quem se presta à pesquisa científica no Brasil. Cabem, no entanto, algumas considerações.

A pesquisa médica deve ser feita com voluntários. Mas o uso de voluntário exige muito bom senso de pesquisador. É importante verificar se as pessoas que se apresentaram como voluntárias entenderam o uso que se fará delas. Aliás, um dos advogados de defesa dos médicos nazistas julgados em Nuremberg argumentou que em todo o mundo se descreviam os participantes dos experimentos médicos como voluntários. O advogado fez, então, uma afirmativa que pode ser válida ainda hoje:

"... é decepcionante a extensão em que os indivíduos são voluntários. (...) Na maioria das vezes (...) acharemos a exploração da ignorância, da tolice, de problemas finan ceiros...". (Katz; 1972: 293). ${ }^{8}$

É preciso entender as razões que levam uma pessoa à decisão de se apresentar como voluntária para determinada pesquisa. Por exemplo, é voluntário o doente crônico para quem se ofereceu esperança de cura? É voluntário o indivíduo que precisa de dinheiro e para quem se ofereceu pagamento? É voluntário o prisioneiro para quem se ofereceu comutar a pena?

Por outro lado, é preciso questionar se as pessoas que assinaram um Termo de Consentimento Livre e Esclarecido, como é exigido pela Resolução CNS 196/96, entenderam a proposta ali contida. Um levantamento antigo 12 feito com participantes de três pesquisas feitas na Universidade Yale mostrou que a compreensão do termo é precária. Não existe pesquisa similar no Brasil. De qualquer forma, muitos documentos encaram o Termo de Consentimento como peça de "isenção de responsabilidades". Para a Resolução 196/96, no entanto, o termo de consentimento deve proteger a dignidade do ser humano, seja ele participante da pesquisa (sobretudo) ou pesquisador. O Termo de Consentimento deve "ser elaborado pelo próprio pesquisador", em linguagem acessível ao possível participante da pesquisa e, ponto de maior importância, ser aprovado pelo CEP.

É verdade que a maioria das pesquisas não envolve riscos de danos maiores do que aqueles associados ao tratamento convencional. Mesmo assim, em função da pesquisa, o médico pode ser obrigado a adotar um acompanhamento agressivo da doença, submetendo o paciente a exames físicos, 
laboratoriais ou radiológicos constantes. Nesses casos, é justo reembolsar o paciente das despesas de transporte e perda do dia de trabalho. Será que isso está, realmente, sendo feito? A Resolução 196/9611 exige que conste no protocolo, o financiamento (orçamento detalhado, fontes, distribuição) e prevê o direito inalienável do participante da pesquisa ao ressarcimento e à indenização. E isso é levado em conta pelo CEP, para aprovação da pesquisa.

No passado, alguns pesquisadores fizeram um número limitado de experimentos em si próprios, durante um período específico de tempo e, usualmente, com propósito bem definido. ${ }^{13}$ Hoje, dado o estágio de evolução em que se encontra a ciência, nem sempre isso seria possível.

Os soldados são, muitas vezes, usados em experimentação. Os experimentos feitos com militares devem servir as mesmas normas da Resolução CNS
196/96. Mas o uso de prisioneiros na pesquisa médica, que foi prática comum no passado, já é incomum. Em tese, prisioneiros são pessoas competentes para decidir se querem ou não participar de uma pesquisa, mas, na prática, são pessoas vulneráveis e sujeitas ao abuso. 8

Finalmente, se o médico opta por fazer pesquisa - além de cumprir seu papel tradicional de exercer a arte de curar - deve estar ciente que essa opção só aumenta sua responsabilidade. O risco é inerente à experimentação. Então a questão ética é determinar quando o médico tem o direito de propor ao paciente abdicar de um tratamento ortodoxo e se expor em um ensaio clínico. Parece claro que essa atitude só é defensável se o tratamento em teste é promissor, a equipe tem competência técnica e o paciente verdadeiramente concorda.

\section{Referências}

1. Ministério da Saúde. CSN (Conselho Nacional de Saúde), CONEP (Comissão Nacional de Ética em Pesquisa). Resolução 251/97. Disponível em: htpp://www.conselho. saude. gov.br [2005 fev 2005].

2. Chow S, Liu J. Design and analysis of bioavailability and bioequivalence studies. New York: Marcel Dekker; 2000.

3. Leite N. Vioxx e a questão da confiança. Folha de São Paulo 2004 out 10; S uplemento Mais: 18.

4. Vieira S, Hossne WS. Pesquisa médica: a ética e a metodologia. São Paulo: Pioneira; 1998.

5. Berger RL. Nazi-science: the Dachau hypotermia experiments. N Eng J Med 1990; 322:1435-40.

6. Smith BF. O tribunal de Nuremberg. Rio de Janeiro: F. Alves; 1970.

7. Levine RJ. Ethics and regulation of clinical research. 2. ed Baltimore: Urban \& Schwarzerberg; 1986.
8. Katz J. Experimentation with human beings. New York: Russel Sage Foundation, 1972.

9. Vieira S, Katz J. O poder médico em questão [entrevista]. Ciência Hoje 1990; 1 1:50-3.

10. Vieira S, Hossne WS. Experimentação com seres humanos. São Paulo: Moderna; 1986.

11. Ministério da Saúde. CNS (Conselho Nacional de Saúde). Resolução n.196/96 regulamenta e estabelece as diretrizes para as pesquisas envolvendo seres humanos no Brasil. Disponível em: htpp://www.conselho.saude.gov.br/ [2005 14 mar].

12. Gray BH. Human subjects in medical experimentation. New York: Wiley; 1975

13. Altman LK. Who goes first? New York: Randon House; 1987.

Recebido em 22 de março de 2005

Versão final apresentada em 22 de abril de 2005

Aprovado em 28 de abril de 2005 